\title{
A FUZZY MODEL FOR EVALUATION, PREDICTION AND CONTROL OF SLURRY EROSION OF DUCTILE MATERIALS
}

\author{
Mahmoud A. El-Sharief, M.A. Hassan and A. Aboul- \\ Kasem \\ Mechanical Engineering Department, Faculty of Engineering, Assiut \\ University, 71516 Assiut, Egypt
}

(Received July 13, 2009 Accepted September 8, 2009).

\begin{abstract}
This paper introduces a fuzzy logic model to evaluate, predict and control the slurry erosion of ductile materials in engineering and chemical applications. There are seven variables which have the most significant influences on the slurry erosion of ductile material, and must be taken into considerations. These are impact angle, time, roundness factor, aspect ratio, particle size, impact velocity and concentration of the particles. By using the fuzzy rules which can be generated based on some experimental observations, a two-layer fuzzy model could be developed to correlate these variables to the slurry erosion (weight loss of material). The model is based on the assumption that the slurry erosion characteristics of ductile materials is an imprecise complex function of many interacting variables, and can be described and evaluated by the theory of fuzzy sets. Membership functions and fuzzy rule-base for application to slurry erosion of 5127 steel as a ductile material are presented in detail to demonstrate the effectiveness of fuzzy logic in modeling such a complex system in an efficient way. This constructed model would facilitate the development of an expert, real-time and integrated system using fuzzy logic technology to monitor and control the level of the slurry erosion process.
\end{abstract}

KEYWORDS: Fuzzy modeling, tribology, slurry erosion

\section{INTRODUCTION}

Slurry erosion is one of the most important factors that assess the success or failure of the machine parts components. However there is no available comprehensive model that can predict the slurry erosion of materials over a wide range of operating conditions. The difficulty arises from the fact that, many variables are affecting the slurry erosion process. These variables include impact angle, impact velocity, concentration of particles, particle size, roundness and aspect ratio etc beside the mechanical properties of target material such as hardens and strength coefficient. Many of these variables are non-linear, independent, or difficult to quantify with crisp numeric precision. Therefore, to some extent, physical models are feasible; the experimental investigations can be very exhaustive with limited applicability. Moreover, there is no empirical model that considers the effect of all variables on the slurry erosion and can be valid for a wide range of applications. 
The theory of fuzzy sets and algorithms developed by Zadeh [1] has been used to evaluate the imprecise linguistic statement directly. Different applications of the fuzzy technique use a specific fuzzy set, which is dependent on the system behavior, and can be identified by the knowledge engineer. Therefore there is no standard method of choosing the proper shape of the membership function for the input and output variables [2]. In fuzzy logic applications, the most widely used shapes for membership functions are; triangular, trapezoidal and arcs. For example, Sutton and Towill [3] concluded that modeling the helmsman action in ship steering the trapezoidal shape is the best shape for that specific application. While for modeling the welding process by robot and imitating the skilled operator hand movement, fuzzimetric arcs were found to be the best shape [2]. Babuska [4] found that constitution of triangle and trapezoidal shapes is the best fuzzy sets for prediction the performance of rock cutting trencher. Many researchers have chosen generalized bell shape membership functions in modeling the surface roughness in grinding process and obtained good results.

This paper suggests a fuzzy model for prediction of the slurry erosion of 5127 steel. The model takes into account most significant variables and covers a wide range of slurry erosion conditions. The generalized bell shape membership functions have been selected to describe the fuzzy variable for the all parameters of the slurry process. Results have been conducted to illustrate the application of the fuzzy logic model for prediction and control of slurry erosion of 5127 steel.

\section{SLURRY EROSION EXPERIMENTS}

The whole phenomenon of slurry erosion is complicated because it is influenced by many factors acting simultaneously. The variation of erosion rate with particle impact angle is of the most interest because of the distribution of wear in fans, turbomachinery, pipes, pumps valves, etc. Materials are classified as either ductile or brittle by their differing erosion rate versus angle of attack curves [9-11]. Slurry erosion experiments were carried out using a slurry whirling arm rig shown schematically in Figure 1 . The designed test rig consists of three main units, namely a specimen rotation unit, a slurry unit and a vacuum unit. Full details of the designed tester have been published (e.g. Al-Bukhaiti et al. [12] and Abouel-Kasem [13]).

The specimen rotation unit provides impact velocity. Two specimens of $23 \mathrm{~mm}$ x $10 \mathrm{~mm} \times 10 \mathrm{~mm}$ in size are clamped in two specimen fixtures. The impact angle can be adjusted by rotating the fixture around its axis. The fixtures are mounted on the ends of the two arms of the rotator which is driven by a variable speed motor. The slurry systems provide a homogeneous stable slurry stream (a mixture of tap water and particles). The falling slurry stream from the $3 \mathrm{~mm}$ in diameter funnel orifice falls with a velocity of $1.62 \mathrm{~m} / \mathrm{s}$ and the impacts every specimen at any pre-set angle between $0^{\circ}$ and $90^{\circ}$, depending on both the orientation of the specimen and the rotational speed of the arm. The distance between the funnel orifice and the specimen surface is $40 \mathrm{~mm}$. The impact angle $\theta$ and impact velocity (v) are correlated to insure the intended value, which can be done from a velocity vector diagram. The slurry test chamber is evacuated by a vacuum system (up to $28 \mathrm{~cm} \mathrm{Hg}$ ) to eliminate aerodynamic effects on slurry system. The test surfaces of the specimens were carefully finished using up to 
3000 grade emery paper. Before and after testing, each specimen was washed in acetone using an ultrasonic cleaner for about 5 min., dried in warm air and then weighed using precision digital balance with sensitivity of $0.1 \mathrm{mg}$. Each test is repeated three times in order to assure the confidence in the experimental results.

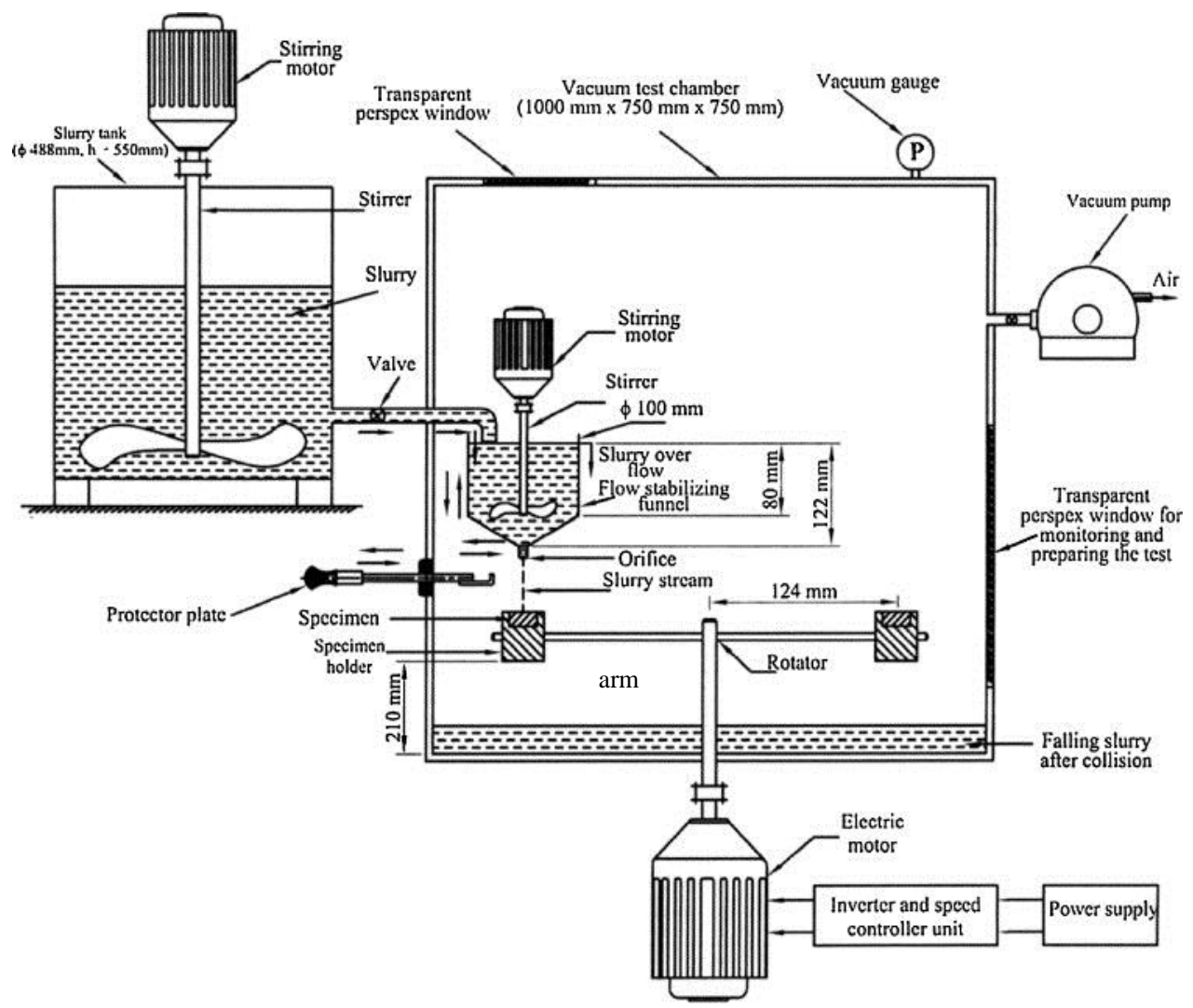

Figure 1 Schematic diagram of the slurry erosion whirling -arm rig [12]

\section{STATISTICAL ANALYSIS OF THE EXPERIMENTAL DATA}

The prediction of slurry erosion and its deviation with slurry erosion conditions and also a desired limit can be obtained for proper control of the most of important erosion parameters. Thus in order to select the variables that are highly related to the magnitudes of slurry erosion, a correlation analysis was carried out using the experimental data. The definition of correlation coefficient between random variable $i$ is given as follows;

$\operatorname{Cor}=\frac{C_{X Y}}{\sqrt{C_{X X} C_{Y Y}}}$

Where $C_{X Y}=\sum_{i}^{N}\left(X_{i}-\bar{X}\right)\left(Y_{i}-\bar{Y}\right), N$ is the number of data and $\bar{X}$ and $\bar{Y}$ are the mean values of the random variables $X$ and $Y$, respectively. 
The correlation factor ( $\mathrm{Cor}$ ) is a statistical parameter designed to have values from $(-1$ to +1$)$. Larger absolute value of ( $\mathrm{Cor}$ ) indicates greater correlation between the random variables.

Figure 2 shows the statistical parameters of the slurry erosion weight loss for angle 30 and 90 degrees. From this figure, it is identified that the correlation coefficient for all parameters greater than \pm 0.5 , Cor $> \pm 0.5$ with the slurry erosion (weight loss).

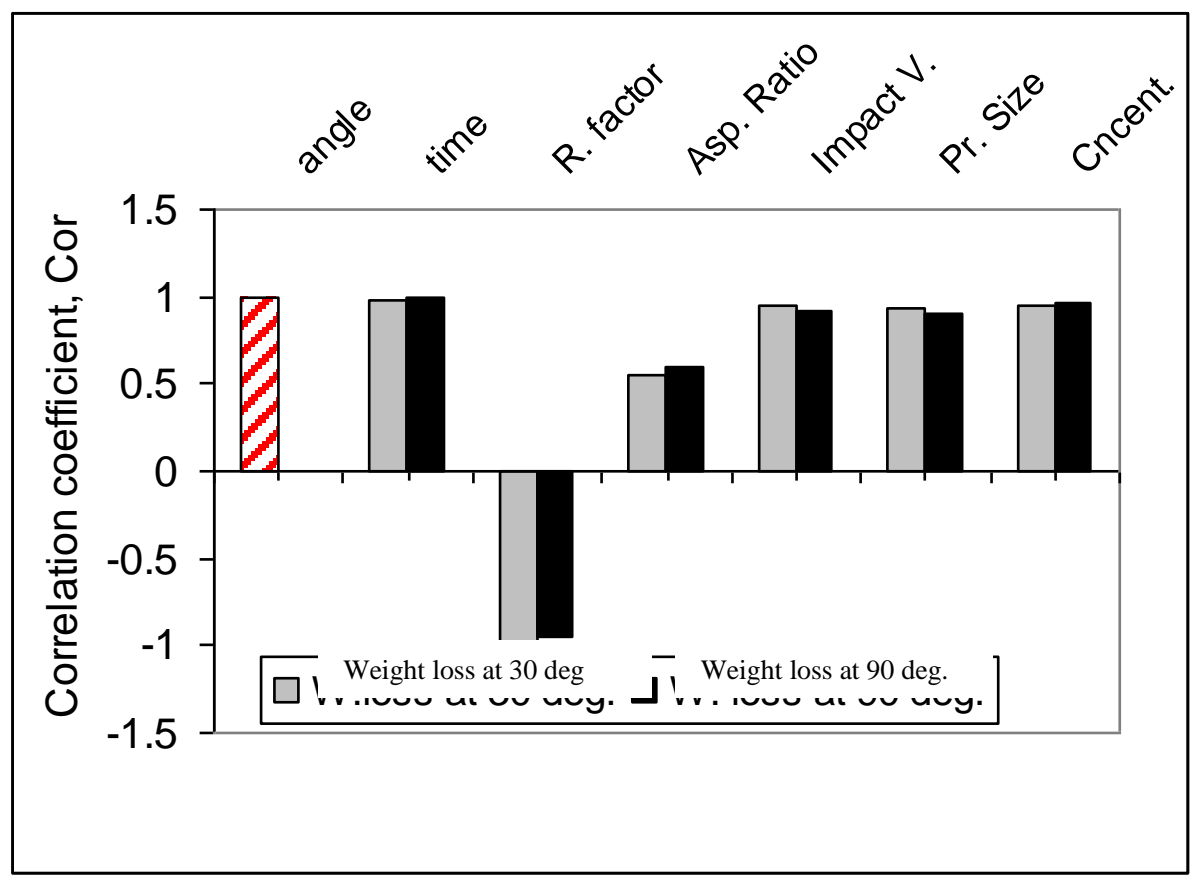

Figure 2 Statistical parameters of the slurry erosion experimental data.

\section{FUZZY MODEL FOR PREDICTION OF SLURRY EROSION}

\subsection{Principles of Fuzzy Logic}

Modeling of systems by fuzzy logic can be employed in a number of ways. There are rule-based fuzzy models [14], fuzzy linear regression models [15], or fuzzy models using cell structure [16]. This paper focuses only on rule-based fuzzy models, i.e., models where the relations between variables are represented by means of fuzzy if-then rules of the form:

(If antecedent proposition then consequent proposition) 
Figure 3 shows a schematic diagram of structure of the fuzzy logic system. The first step of fuzzy logic system is to employ the inputs or some inputs into a fuzzification process. In the fuzziffcation process, the input data (digital, precise/imprecise) will undergo some translation into linguistic quantity such as, very low, low, medium, high, very high, etc. This fuzzy logic translation process is concerned with the continuous transition from truth to falsity states, as opposed to the discrete true/false transition binary logic. So that fuzzification process provides a continuous measure of the potentiality of subset in belonging to another subset. Therefore the output is a fuzzy degree of membership in the qualifying linguistic set (always the interval between 0 and 1 ).

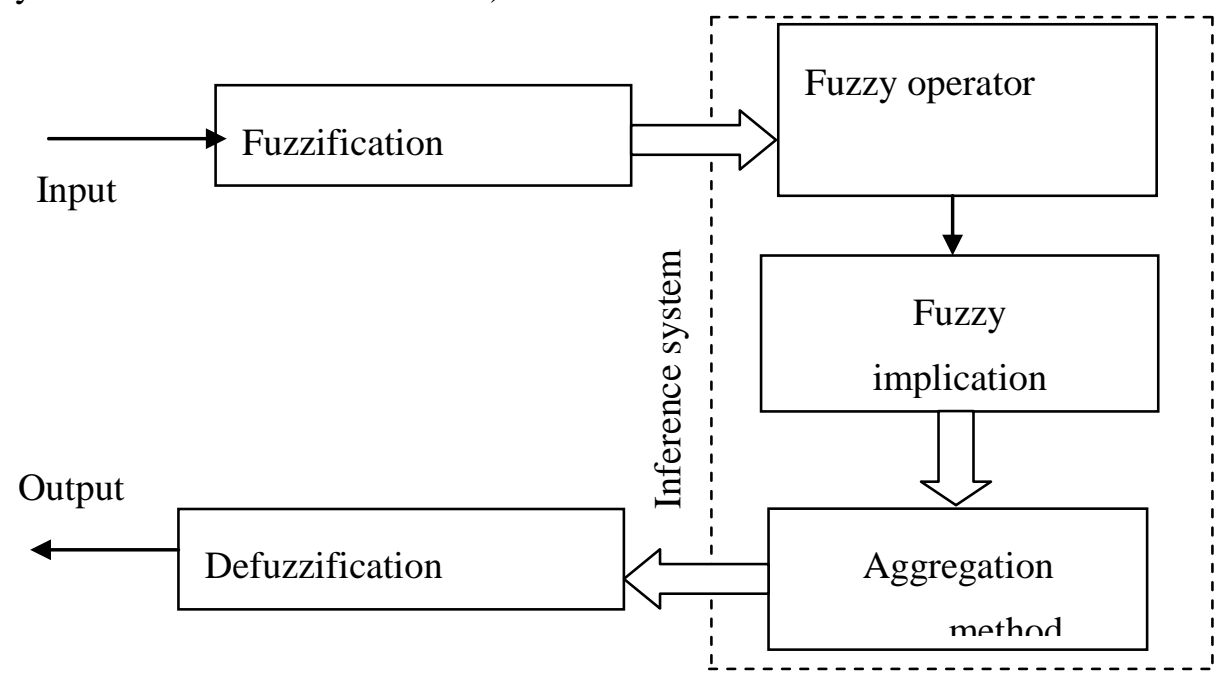

Figure 3 Schematic diagram showing principles of the fuzzy logic

In the second step, once the inputs have been fuzzified, we have to apply the fuzzy operator for each rule (if the antecedent of a given rule has more than one part) in the rule base to obtain one number that represents the antecedent for that rule. For example if the input to the fuzzy operator is three membership values from fazzified input variables. The output is single truth value. In the most common fuzzy logic systems AND operator is taken to be min (minimum) and prod (product) methods. While OR operator is replaced as max (maximum) and the probabilistic OR method probar [15]. The present model uses the truth value, $\mu^{i}$ of the $i$ th rule and can be calculated by;

$\mu^{i}=\min \left\{L_{1}^{i}\left(x_{1}\right), L_{2}^{i}\left(x_{2}\right), L_{3}^{i}\left(x_{3}\right)\right\}$

Where, $L_{1}^{i}\left(x_{1}\right), L_{2}^{i}\left(x_{2}\right)$ and $L_{3}^{i}\left(x_{3}\right)$ are the membership degrees of the linguistic variables, $L_{1}^{i}, L_{2}^{i}$ and $L_{3}^{i}$, respectively.

In the third step, implication method should be applied for each rule. Implication means reshaping of the consequent (a fuzzy set represented by membership function) of each rule in the rule base using a function associated with the antecedent 
(a single number). The input for the implication process is a single number and the output is a fuzzy set. The implication methods are the same functions that are used by the AND method: min (minimum), which truncates the output (consequent) fuzzy set, and prod (product), which scales the output fuzzy set [15].

In the fourth step, since decisions are based on the testing of all the rules in the base rule system, the rules must be aggregated in some manner in order to make a decision. Aggregation is the process by which the fuzzy sets that represent the outputs of each rule are combined, using the max operator, into a single fuzzy set. Combination only occurs once for each output variable in a fuzzy inference system. The input of the aggregation process is the list of truncated or scaled output functions returned by the implication process for each rule, while the output is one fuzzy set for each output variable. The order of the aggregation method is unimportant, because the method is commutative.

In the fifth step, defuzzification process should be applied. The input is the aggregated output fuzzy set and the output is a single number. The aggregated fuzzy set encompasses a range of output values and so must be defuzzified in order to obtain a single value from the set. There are five defuzzification methods: centroid, bisector, middle of maximum, largest of maximum, and smallest of the maximum. The most popular defuzzification method is the centroid of calculation [16]. This method is used in the present model, accordingly the pre-determined slurry erosion, $(\mathrm{Se})$ is given as;

$$
W=\frac{\sum_{i}^{n} \mu^{i} \cdot W^{i}}{\sum_{i}^{n} \mu^{i}}
$$

Where, $n=$ number of rules in the primary rule base, $W^{i}=$ consequent value of slurry erosion for the $i$ th rule.

Until now, the main power of fuzzy logic depends on the proper selection of the membership functions $\mu(x)$ and fuzzy rules that can simulate high non-linearity and complex systems. The present work presents that membership functions are defined by six parameters $P=\{\alpha, \beta, \gamma, \delta, \eta, \lambda\}$, such that:

$$
\mu(x)=\left\{\begin{array}{cc}
0 & x \notin[\alpha, \lambda] \\
2\left(\frac{x-\alpha}{\gamma-\alpha}\right)^{2} & \alpha<x \leq \beta \\
1-2\left(\frac{x-\alpha}{\gamma-\alpha}\right)^{2} & \beta<x \leq \gamma \\
1 & \gamma \leq x \leq \delta \\
2\left(\frac{\lambda-x}{\eta-\alpha}\right)^{2} & \delta<x \leq \eta \\
1-2\left(\frac{\lambda-x}{\eta-\alpha}\right)^{2} & \eta<x \leq \lambda
\end{array}\right.
$$

Where, $\quad \beta=\frac{(\alpha+\gamma)}{2}, \quad \eta=\frac{(\delta+\lambda)}{2}$ 
The above membership function is frequently used in fuzzy logic modeling. Figure 4 shows the definition of the membership function, $\mu(x)$ expressing the degree of belonging of the crisp value of $x$ to a specific fuzzy term (e.g. very low, low, high, etc.).

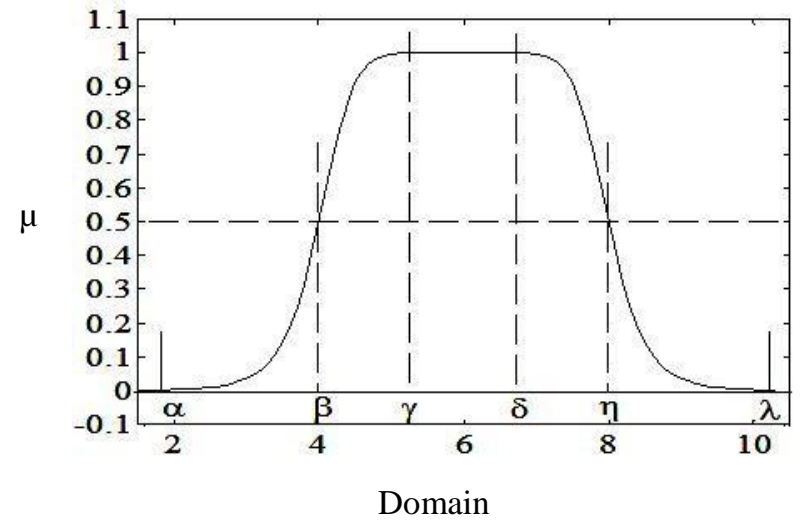

Figure 4 Definition of the generalized membership

\subsection{Fuzzy Algorithm for Slurry Erosion Prediction}

Figure 5 shows the structure of the developed fuzzy model. It consists of two rule bases, primary rule-base and modifier rule-base, which receive seven input variables that affect the slurry erosion of material. The definition of the membership functions for the primary variables is shown in Figure 4. The shape of these membership variables can be obtained from the experimental data by cylindrical projection clustering routine [7]. The fuzzy rules describing the effect of these seven variables are obtained from two sources:

(a) Experimental observations for six primary variables, i.e. roundness factor, aspect ratio, particle size, impact velocity, time and concentration of the particles (shemy wear).

(b) The impact angel been rarely investigated experimentally, so that we have a lack of knowledge and therefore that variable is called modifier variable. The membership functions for the impact angle modifier variable are given by equation (4). The fuzzy rules concerning the modifier variable are obtained from metal forming mechanics point of view.

The way in which the inference engine works is as follows:

(1) The numerical values of six primary variables namely, roundness factor, aspect ratio, particle size, impact velocity, time and concentration of the particles are input to the primary rule base as shown in Figure 4. These variables produce an output estimation of the fuzzy variable; slurry erosion.

(2) The output fuzzy variable from the primary rule-base is input to the modification rule base to modify slurry erosion in the final output.

(3) At the same time, impact angle modifier variable is input to the modifier rulebase to modify and calculate the final output for slurry erosion.

In principle, the primary rule base contains 128 rules; however, many of these rules have no practical relevance. So, in one hand only 60 rules are of the most significant, and on the other hand 4 rules are used by the modifier rule-base. 


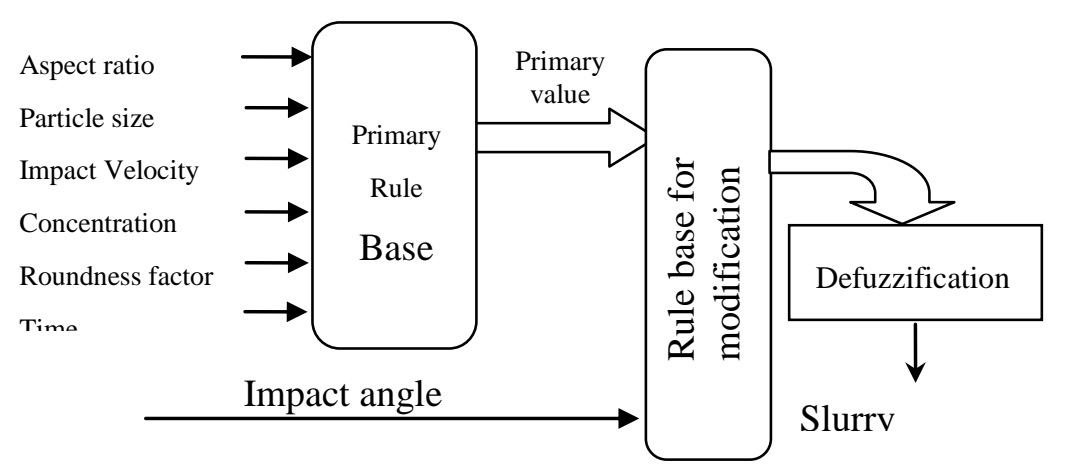

Figure 5 Structure of the developed fuzzy model that predicts the slurry erosion of material (Single line represents numerical variables, double line representing fuzzy

\subsection{Fuzzy System for Modifying Predetermined Slurry Erosion}

The values of slurry erosion, $W$, determined from the primary rule-base depends only on, material, particle size, impact velocity, concentration, aspect ratio, and time. Since in the present model the developed primary rules for calculating the slurry erosion was based on the experimental results that was carried out in our laboratory for three different impact angles, therefore the calculated results should be modified to appropriate magnitude according to the degree of the impact angle.

To determine weighing factor $(F)$ according to the impact angle $(\phi)$ two fuzzy rules are introduced as follows:

$$
\begin{array}{ll}
R_{1} \text { : if } \phi \text { is Big then } & F_{B}=1-1 / \sqrt{W^{s}-W+1} \\
R_{2} \text { : if } \phi \text { is Small then } \quad F_{S}=1 / \sqrt{W^{s}-W+1} & -1
\end{array}
$$

Here, Big and Small are variables for which the membership degrees are determined by the following membership functions $\mu_{1}(\phi)$ and $\mu_{2}(\phi)$, respectively.

These fuzzy functions are obtained from empirical relation between slurry erosion and impact angle, where $\phi$ the impact is angle variable and $W^{s}$ is the erosion at the saturation level Membership functions $\mu_{1}(\phi)$ and $\mu_{2}(\phi)$ determine the membership degrees (between 0 and 1) of a given $\phi$ for the linguistic variable Big and Small. The weighing factor $F$ for a given impact angle $\phi$ is calculated as follows:

$$
F=\frac{\mu_{1}(\phi) \times F_{B}-\mu_{2}(\phi) \times F_{S}}{\mu_{1}(\phi)+\mu_{2}(\phi)}
$$


The modified value of slurry erosion, $W^{\prime}$, for the predetermined slurry erosion, $W$ is obtained as:
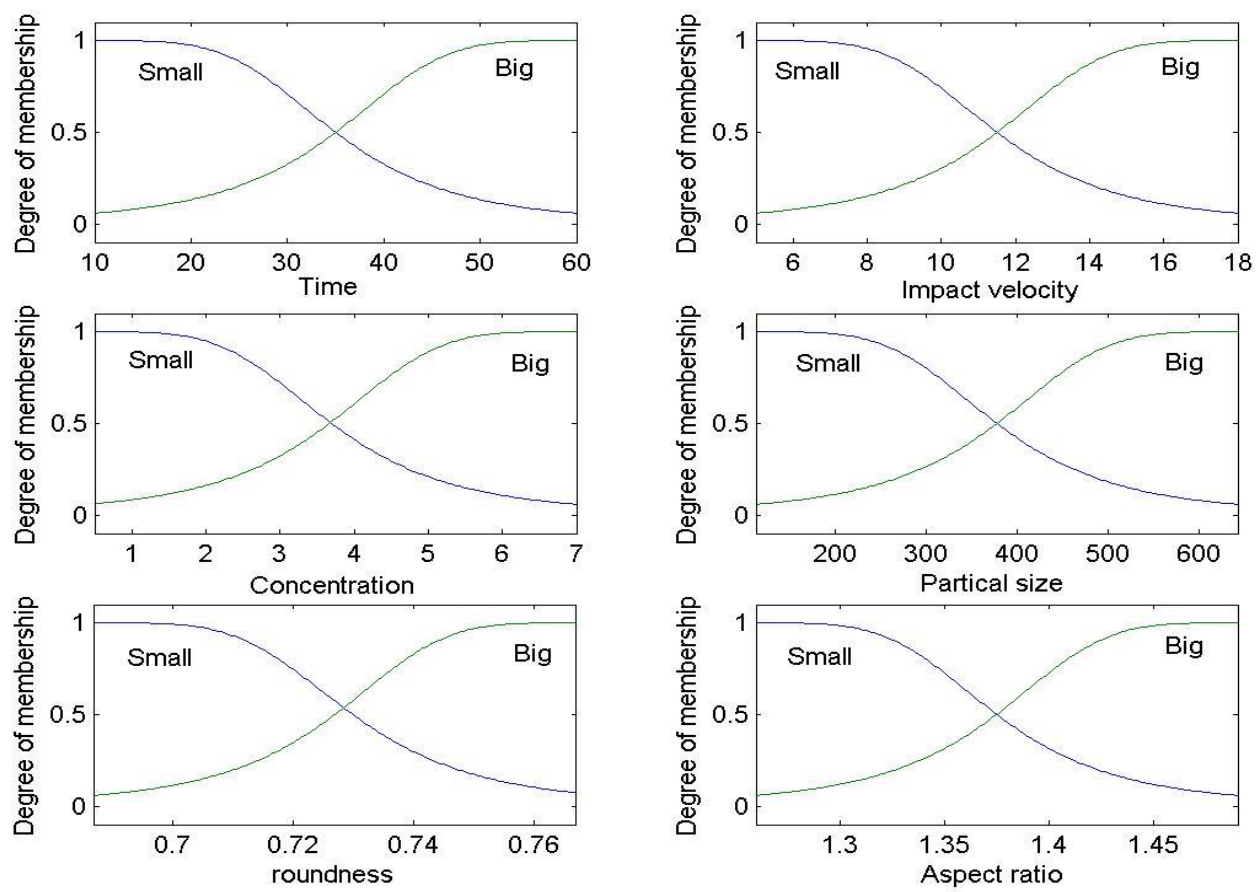

$$
W^{\prime}=(1-F) W
$$

Figure 6 Membership functions for input primary variables.

\section{RESULTS AND DISCUSSION}

Using the currently developed fuzzy model, the slurry erosion variations of 5127 steel were obtained from the six input variables, but because of axis limitation, the combined effect of all six variables on the output variation of slurry erosion cannot be shown graphically. Fig. 6 shows the slurry erosion of each two input parameters together and the other parameters are taken constant at their average values. Fig.6 (a) presents that the slurry erosion increases with increasing impact velocity and particle size to a maximum value and then gradually decreases as the particle size exceeds 400 . Fig.6 (b) presents the variations of the slurry erosion with the combined action of particle concentration and time. It decreases gradually with decreasing with increasing concentration and increases with increasing time. Fig.6 (e) exhibits the slurry erosion variations with the aspect ratio and impact velocity of the particles; it decreases with increasing aspect ratio and impact velocity. These results are in good agreement with 
experimental trends. For any arbitrary seven numerical values corresponding to the seven input variables, amount of slurry erosion can be determined.

Figure 7 shows output fuzzy surface of comparison between the predicted and the experimented data of 5127 steel slurry erosion at different parameters. At the same conditions the measured slurry erosion is slightly differ from predicted one, but the same trends are obtained from the fuzzy model and the results show good agreement with the measured ones.
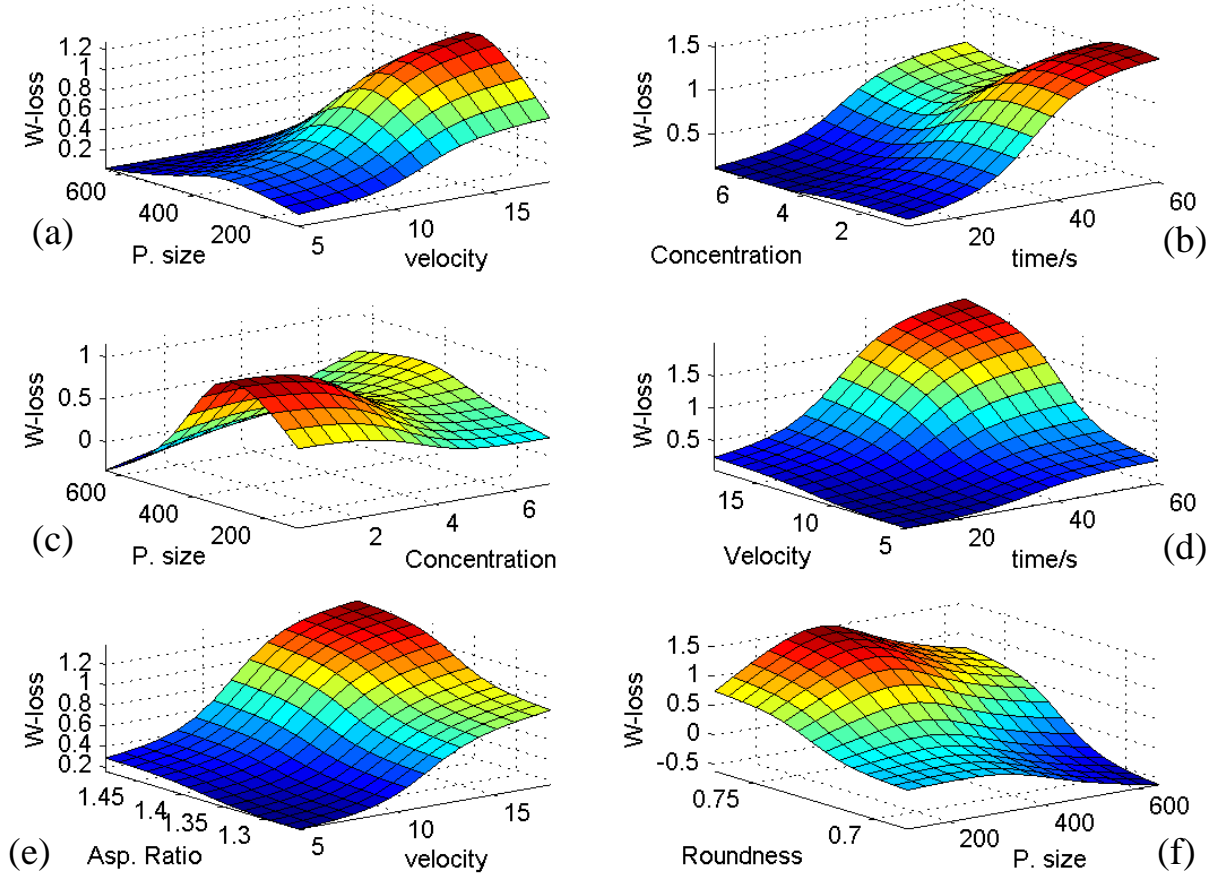

Figure 7 Output fuzzy surface of slurry erosion for input parameter

\section{COMPARISON}

Figures 8 and 9 show a comparison between predicted and measured slurry erosion of 5127 steels for impact angles $90^{\circ}$ and $30^{\circ}$, respectively. Both figures show gradation of the output fuzzy surface of scullery erosion with the combined change of particle size and impact velocity. At same values of impact velocity and particle size, the measured and predicted values matches very well. The maximum percentage error ranges between model and experimental data is from $+14 \%$ to $-7 \%$. From these comparisons it can be relied on model values if the experimental conditions are difficult to be existed. 


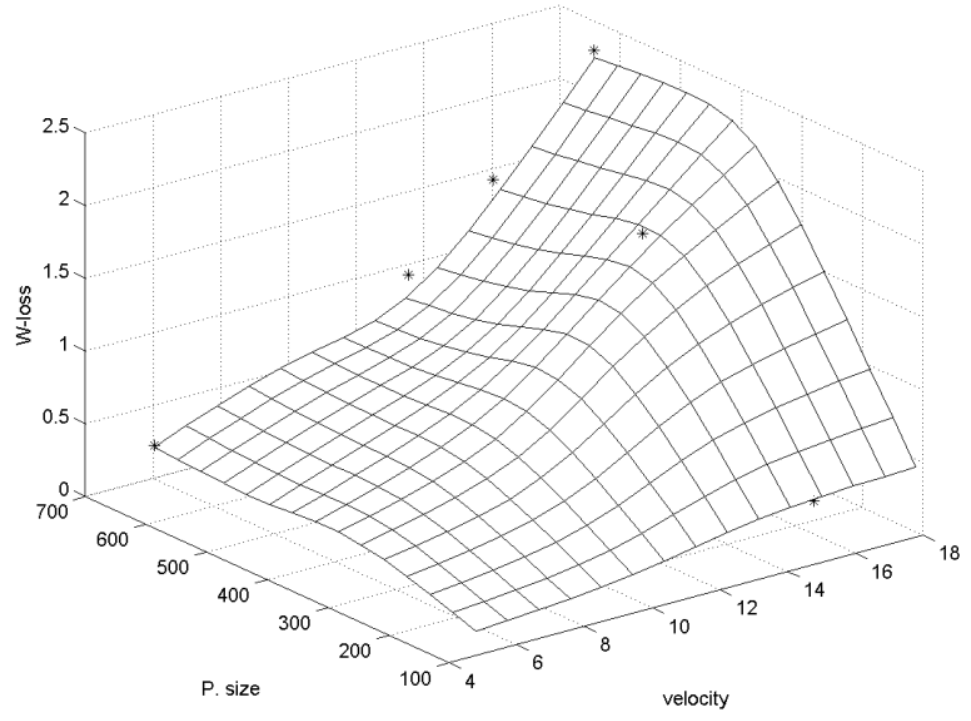

Figure 8 Comparison between experimental and predicted erosion values, impact angle 90 degrees.

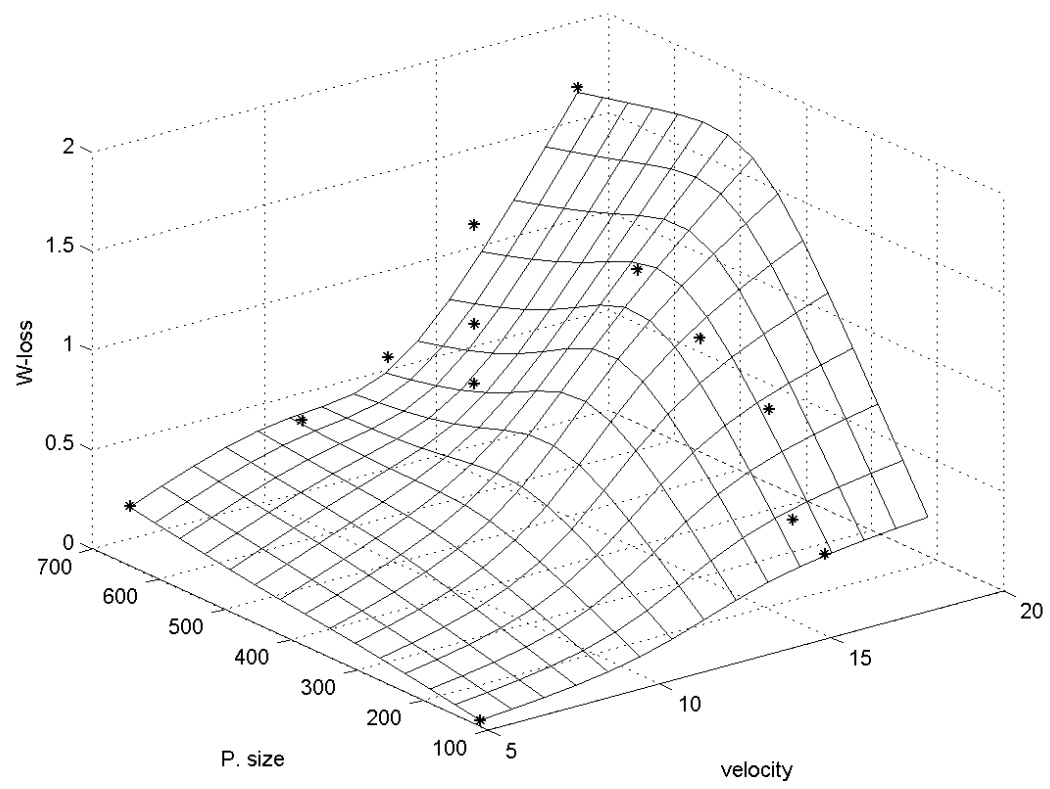

Figure 9 Comparison between experimental and predicted erosion values, impact angle 30 degrees 


\section{CONCLUSIONS}

In this paper, a fuzzy logic model was proposed to predict and control the slurry erosion of a ductile material. Six variables (particle size, impact velocity, concentration, aspect ratio, roundness, time, and impact angle) were taken into consideration, which are of the most influential on the slurry erosion of material turbo machinery. The membership functions, primary and modifier rule-bases have been presented in detail. The effectiveness and the high performance of the model have been demonstrated by predicting and generating the slurry erosion data of 5127 steel. Results of the developed fuzzy model are in good agreement with the experimental data and an intuitive tribology point of view.

The proposed model suggests the possibility of developing an expert real time and integrated system using fuzzy logic technology to control and monitor the slurry erosion in turbo machinery and micromachining of waver substrates.

\section{REFERENCES}

[1] Zadeh, L. A. Fuzzy sets, Inf. Control, Vol. 8, pp 338-353, 1965.

[2] Kouati, I. \& Jones, B., "An improved design procedure for fuzzy control system", Int. J. Mach. Tool Manufact. Vol. 31, pp 102-122, 1991.

[3] Sutton, R. \& Towill, D. R., "An introduction to the use of fuzzy sets in the implementation of control algorithm", J. Inst. Eect. Radio Engrs, Vol. 55, pp 357-367, 1985.

[4] Babuska, R. , "Fuzzy Modeling for Control", Kluwer Academic Publishers, 1998.

[5] Ali, Y.M. \& Zhang, L. C., "Surface roughness prediction of ground components using a fuzzy logic approach", J. Mat. Pro. Tech., Vol. 89, pp 561-568, 1999.

[6] Zadeh, L., "Outline of a new approach to analysis of complex systems and decision process”, IEEE Trans. Systems, Man Cybernetics Vol. 1, pp 28-44, 1973.

[7] Tanaka, T. S., "Linear regression analysis with fuzzy model", IEEE Trans. Systems, Man \& Cybernetics, Vol. 12, pp 903-907, 1982.

[8] Smith, S. \& Comer D., "A computational approach to fuzzy logic controller design and analysis using cell state space methods: In Kandel and Langholz Eds", Fuzzy Control System, pp 398-427, 1994.

[9] Burstein, G.T., Sasaki, K., 2000, "Effect of Impact Angle on the Slurry Erosion-Corrosion of 304 L Stainless Steel," Wear, 240, pp 80-94

[10] Oka, Y.I, Ohongi, H., Hosokawa, T., Matsumura, M., 1997, "The Impact Angle Dependence of Erosion Damage Caused by Solid Particle Impact," Wear, 203-204, pp 573-579

[11] Clark, H.M., Wong, K.K., 1995, "Impact Angle, Particle Energy and Mass Loss in Erosion by Dilute Slurries," Wear 186 - 187, pp 454-464.

[12] Al-Bukhaiti, M.A., Ahmed, S.M., Badran, F.M .F, Emara, .K.M., 2007, "Effect of Impact Angle on Slurry Erosion Behavior and Mechanisms of 1017 Steel and High-Chromium White Cast Iron," Wear, 262, pp 1187 - 1198.

[13] Abouel-Kasem, A., Al-bukhaiti, M.A., Emara, K.M. and Ahmed, S.M., "Design and Performance of Slurry Tester," to be puplished. 
[14] Driankov, D. Hellendoorn, H., and Reinfrank, M.," Mosel Based Fuzzy Control", Springer-Verlag Berlin Heidelbreg, 1997.

[15] Rainer, P., and Driankov, D., H, “An Introduction to Fuzzy Control”, Second Edition, Springer-Verlag Berlin Heidelbreg, 1996.

[16] Yamaguchi, K. and Takakura, N., "Effects of strain rate and temperature on deformation resistance of stainless steel", Proceeding of the 6th Int. conf. on Mechanical behavior of Material, Kyoto, Japan, 1991.

نموذج غامض لتقييم والتتبؤ والتحكم في كمية التآكل الناتجة فى المواد اللانة التى تتعرض لتصادم مع السوائل

د. محسن عبد النعيم د. محمود أحمد الثربف

\author{
د. أحمد أبو القاسم \\ قسم الهندسة الميكانيكية, كلية الهندسة بجامعة أسيوط
}

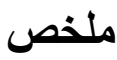

هذا البحث يقدم نموذج غامض لتقييم والتتبؤ والتحكم في كمية التآكل فى المواد المطلية الناتجة من تعرضها الى تصادم مع أي خليط كيمائي سائل وله نطبيقات كثيرة في مجال الهندسة الكيميائية. يوجد

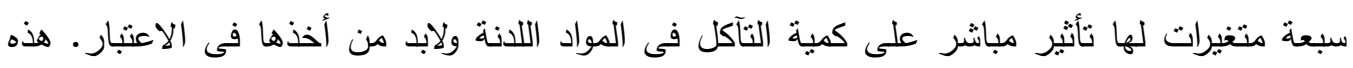

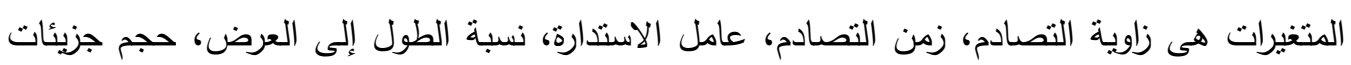

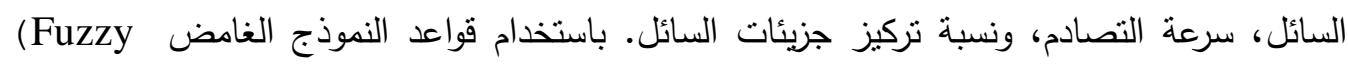

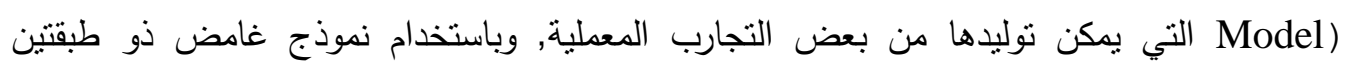
(two-layer fuzzy model)

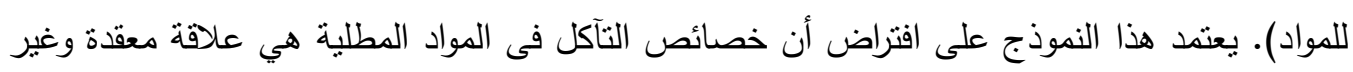

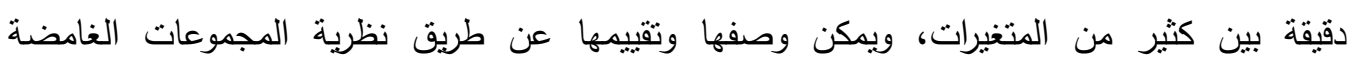
(Membership functions and fuzzy مناقات العضوية والقاعدة الغامضة (Fuzzy sets)

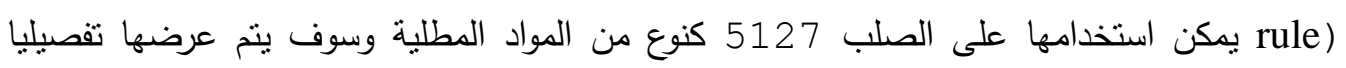
لوصف مدى صلاحية وكفاءة هذا النموذج لمنل هذه الأنظمة المعقدة. 